\title{
ARTIGO COMEMORATIVO AO CINQUENTENÁRIO DO TRIBUNAL ADMINISTRATIVO DE RECURSOS FISCAIS DO RIO GRANDE DO SUL: 1959-2009
}

\section{Gentil André Olsson ${ }^{1}$}

\section{RESUMO}

O artigo traz um histórico do Tribunal Administrativo de Recursos Fiscais (TARF), iniciando pelo Conselho Estadual de Contribuintes (CEC): sua denominação, sede, competência, composição, representação da Fazenda junto ao Conselho Estadual de Contribuintes e sessão inaugural. Discorre sobre o TARF, antes da vigência da Lei ${ }^{\circ}$ 6.537/73: a nova denominação, sede, competência, composição, representação da Fazenda Pública
Estadual junto ao Tribunal e sessão inaugural como Tribunal Administrativo de Recursos Fiscais. Apresenta, ainda, a configuração atual do TARF: generalidades, competência, composição, atribuições do Presidente do Tribunal, atribuições do SecretárioGeral do Tribunal, configuração das Câmaras do Tribunal, competência das Câmaras, atribuições dos Presidentes das Câmaras, atribuições dos Juízes, impedimentos, atribuições dos Secretários das Câmaras, defesa da Fazenda Pública Estadual junto

1 Mestre em Direito. Presidente do Tribunal Administrativo de Recursos Fiscais do Rio Grande do Sul (TARF) e Professor de Direito Tributário e Direito Financeiro da Faculdade de Direito da Universidade Federal do Rio Grande do Sul (UFRGS). Currículo: http://buscatextual.cnpq.br/buscatextual/visualizacv.jsp?id=K4745452J6. Endereço profissional: Av. João Pessoa, 80, Centro, Porto Alegre, RS, Brasil. 90.040000. Endereço eletrônico: casagrande@direito.ufrgs.br. 
ao TARF, serviços auxiliares, avocação de julgamento pelo Secretário de Estado da Fazenda, súmulas de jurisprudência do TARF, Regimento Interno e atuação do sujeito passivo junto ao Tribunal (partes, representantes e procuradores).

Descritores: TARF: história. TARF: organização \& administração. TARF: recursos humanos. Direito administrativo: Rio Grande do Sul. Direito tributário: Rio Grande do Sul.

\section{BREVE HISTÓRIA DO TRIBUNAL ADMINISTRATIVO DE RECURSOS FISCAIS (TARF)}

O Conselho Estadual de Contribuintes (CEC) e o Tribunal Administrativo de Recursos Fiscais, antes da vigência da Lei $n^{\circ}$ 6.537/73.

\subsection{O Conselho Estadual de Contribuintes (CEC)}

O Tribunal Administrativo de Recursos Fiscais do Rio Grande do Sul foi criado pela Lei RS $n^{0}$ 973, de 16 de janeiro de $1950,{ }^{2}$ sob a denominação ${ }^{3}$ de Conselho Estadual de Contribuintes (CEC). ${ }^{4}$

Sua primeira sede (provisória) foi no terceiro andar (salas 308 e 310) do $n^{\circ} 48$ da Rua Júlio de Castilhos, onde esteve em "pleno funcionamento" de 10.05.51 (data da Aprovação do

2 Lei com vigência retroativa a 1 de janeiro de 1950. Alterada pelas Leis n. 1.368, de 27.12.1950 e 2.054, de 18.03.1953.

3 “Art. $1^{\circ}$ - Fica instituído o Conselho Estadual de Contribuintes, que funcionará como tribunal 'mixto' administrativo, nos termos do art. 241 da Constituição Estadual.” (sic). A Constituição do Estado do Rio Grande do Sul, de 1945, em seu art. 241, determinava: "Serão criados em lei um ou mais tribunais mistos, administrativos, para o julgamento, em última instância, de questões entre contribuintes e a fazenda estadual ou municipal" (Rio Grande do Sul, 1945).

4 Atos normativos anteriores, relativos à administração fazendária e julgamento de matéria de natureza financeira e tributária e atos relativos à organização da Procuradoria Fiscal do Estado:

a) Ato $n^{\circ} 223$, de 02.05.1890 instituiu a Diretoria do Contencioso, que constituía, com duas outras Diretorias, a Administração Central do Tesouro do Estado;

b) Regulamento do Tesouro de Estado, aprovado pelo Decreto $n^{\circ}$ 1.081, de 23.04.1907, que atribuiu ao Secretário de Estado dos Negócios da Fazenda a competência para julgar recursos interpostos das decisões das repartições e empregados fiscais (art. $5^{\circ}$, $\S 10)$ e ao Procurador Fiscal (de livre nomeação e demissão do Presidente do Estado) a competência de velar pela execução das leis fiscais (art. 13);

c) Decreto $n^{\circ} 3.002$, de 8/8/1922: Interpretou as disposições do Decreto $n^{\circ} 2.578$, de 
seu primeiro Regimento Interno) até 28.06.51. Em 14.09.51, ${ }^{5}$ passou a funcionar nas salas 1109 a $1111\left(11^{\circ}\right.$ andar) do $\mathrm{n}^{\circ} 410$ (Edifício Sulacap) da Av. Borges de Medeiros, tendo realizado sua última sessão, no local, em 09.07.52. A partir de 23.07.52, funcionou no $4^{\circ}$ andar (conjuntos $42 \mathrm{e}$ 45) do $n^{\circ} 90$ (Edifício Condor) da Rua Andrade Neves, onde permaneceu até 12.08.57 e a partir de 19.08 .57 , passou a operar no ${ }^{0} 712$ da Rua Duque de Caxias, ${ }^{6}$ onde ficou até 26.05.61, ${ }^{7}$ sendo que a partir de 23.01.59, ostentou a atual denominação - Tribunal Administrativo de Recursos Fiscais.

A competência do Conselho de Contribuintes consistia em:

a) julgar, em segunda e última instância administrativa, os recursos ${ }^{8}$ das decisões em matéria de cobrança ou lançamento de impostos, taxas

31.05.1920, que aprovou o Regimento Interno do Tesouro do Estado e do Decreto ${ }^{\circ}$ 2.646, de 04.09.1920, que consolidou as atribuições do Ministério Público, no que se referia à Procuradoria Fiscal e a exatores em geral e declarou as suas atribuições;

d) Decreto-lei ${ }^{\circ}$ 411, de 30.10 .43 (vigência: 01.01.44) - Deu nova organização à Procuradoria Fiscal do Estado, conceituo-a como o órgão técnico-jurídico da Secretaria de Estado dos Negócios da Fazenda e determinou a sua competência;

e) Decreto-lei no 412, de 30.10 .43 (vigência: 01.01.44) - Reuniu na Procuradoria Fiscal do Estado (reestruturada) os antigos Procuradores Fiscais e os Funcionários da extinta Diretoria do Tesouro do Estado;

f) Decreto ${ }^{\circ}$ 5.103, de 11.08.54 - Criou a Procuradoria-Geral do Estado e integrou nela a Procuradoria Fiscal;

g) Decreto $n^{\circ}$ 8.507, de 13.01.58 - Reconduziu a Procuradoria Fiscal do Estado à Secretaria da Fazenda (integrada por seis cargos, com lotação na Secretaria da Fazenda), mantendo a competência atribuída pelo Decreto-lei no ${ }^{\circ}$ 411/43.

5 As datas iniciais de cada período correspondem, sempre, à primeira sessão realizada naquele local e às datas finais do período; correspondem à data da última sessão realizada no respectivo local, conforme publicação das pautas no Diário Oficial do Estado. 6 Prédio que hoje não existe mais, já foi demolido.

7 Data da última sessão registrada no $n^{0} 712$ da Rua Duque de Caxias, já com a denominação de Tribunal.

8 Os recursos de ofício tinham que ser interpostos no prazo de 10 dias pela autoridade julgadora de primeira instância que decidisse favoravelmente ao sujeito passivo. O prazo para interposição de recurso voluntário era de 30 dias da ciência da decisão de primeira instância que não acolhera a impugnação e, se versasse sobre débito vencido, estava condicionada ao depósito prévio de $50 \%$ do valor, ou fiança idônea. A lei $\mathrm{n}^{\circ}$ 2.054/53 conferiu prazo em dobro (contado do vencimento do prazo de 30 dias para a interposição de recurso voluntário) para a autoridade julgadora interpor recurso obrigatório, quando a decisão fosse suscetível a ambos os recursos. 
e contribuições ${ }^{9}$ decorrentes de leis ou regulamentos e das decisões proferidas em matéria de consulta;

b) sugerir ao Secretário da Fazenda as providências que entendesse necessárias às boas relações entre o Fisco e os contribuintes;

c) elaborar o seu Regimento Interno; ${ }^{10}$

d) requisitar os servidores necessários ao funcionamento de sua Secretaria;

e) excepcionalmente, quando entendesse aplicável julgamento por equidade, ${ }^{11}$ encaminhar o processo, com parecer do relator nesse sentido, ao Secretário da Fazenda, para decisão.
O Conselho era composto ${ }^{12}$ de seis conselheiros (ou seus respectivos suplentes) nomeados pelo Governador do Estado, respeitada a paridade entre a representação da Fazenda Pública e a representação dos contribuintes, e de um "Ministro Presidente" (ou seu suplente), ${ }^{13}$ todos com mandato de dois anos. ${ }^{14}$ Os três membros representantes da Fazenda Pública, ${ }^{15}$ e seus suplentes, eram indicados pelo Secretário de Negócios da Fazenda, ${ }^{16}$ dentre "funcionários de reconhecida competência em matéria fiscal". Cada

9 É de se observar que, em razão do entendimento da época, posteriormente consolidado no art. $5^{\circ}$ do CTN (literalmente: "Os tributos são impostos, taxas e contribuições de melhoria"), sua competência compreendia todos os tributos estaduais.

10 Em Sessão de 10 de abril de 1951, foi aprovado o primeiro Regimento Interno do Conselho Estadual de Contribuintes do Rio Grande do Sul e foi publicado no Diário Oficial do Estado do Rio Grande do Sul, em 10 de maio de 1951 (Rio Grande do Sul, 1951).

11 O Conselho não tinha competência para julgar por equidade, podendo, apenas, sugerir tal julgamento ao Secretário da Fazenda.

12 Os membros do Conselho percebiam Cr\$200,00, por sessão a que compareciam, até o limite de Cr\$1.000,00, por mês.

13 O primeiro Presidente do Conselho e seu suplente, designados em ato publicado no Diário Oficial de Estado, de 14.02.51, foram Moacyr Dorneles e Carlos Alberto Leão dos Reis, respectivamente.

14 Admitida a recondução por mais um período, mediante indicação da respectiva entidade representada. A Lei $n^{0} 2.054 / 53$, suprimiu a expressão "por mais um período".

15 Os primeiros representantes da Fazenda, designados em ato publicado no Diário Oficial de Estado, de 14.02.51, foram César Couto, Manoel Marques Leite e Gervásio Kramer da Luz.

16 A Lei no 1.368, de 27 de dezembro de 1950, introduziu a denominação: 'Secretário de Estado dos Negócios da Fazenda’. 
um dos três membros representantes dos contribuintes, e seus respectivos suplentes, era indicado em lista tríplice, ${ }^{17}$ respectivamente, pela Fede-ração das Associações Comerciais do Rio Grande do Sul; ${ }^{18}$ pela Federação das Associações Rurais do Rio Grande do Sul ${ }^{19}$ e pela Federação das Indústrias do Rio Grande do Sul. ${ }^{20}$ Inicialmente, o presidente e seu suplente deveriam ser indicados pelo Tribunal de Contas do Estado do Rio Grande do Sul. A partir de 1951, ${ }^{21}$ a designação (e a dispensa) do Presidente do Conselho e do seu suplente passou a ser de livre escolha do Governador do Estado, "dentre bacharéis em direto, de reconhecida capacidade, de indiscutível idoneidade e equidistantes dos interesses dos contribuintes e do fisco". O Conselho funcionava com cinco membros, no mínimo, e deliberava por maioria de votos, cabendo ao
Presidente exclusivamente o voto de desempate. Em 1953, foram criadas "funções gratificadas" para Chefe de Secretaria, Secretário das Sessões e Assistente da Presidência. ${ }^{22}$

Atuava junto ao Conselho um dos Procuradores Fiscais do Estado, ${ }^{23}$ designado pelo Governador, com a atribuição de velar pelos interesses da Fazenda, nas questões submetidas ao Órgão. Ao Procurador Fiscal, assim como ao contribuinte (ou seu representante), na condição de partes no processo, era facultado:

a) requerer diligências assecuratórias do interesse ou direito fiscal em causa;

b) fazer sustentação oral;

c) pedir reconsideração ${ }^{24}$ das decisões não unânimes do Conselho.

A primeira sessão de julgamento de que temos registro - Acórdãos $n^{\circ} 1$

17 A Lei $\mathrm{n}^{\circ}$ 1.368, de 27 de dezembro de 1950, aumentou para quatro o número de nomes apresentados na lista de cada entidade.

18 O primeiro Conselheiro representante da FEDERASUL, designado em ato publicado no Diário Oficial de Estado, de 14.02.51, foi Arnaldo Reinert.

19 O primeiro Conselheiro representante da FARSUL, designado em ato publicado no Diário Oficial de Estado, de 14.02.51, foi Aramy Silva.

20 O primeiro Conselheiro representante da FIERGS, designado em ato publicado no Diário Oficial de Estado, de 14.02.51, foi Paulo Ernesto Dohms.

21 Por força da Lei n ${ }^{\circ} 1.368$, de 27 de dezembro de 1950.

22 Lei no 2.055, de 18 de março de 1953.

23 Relativamente à Procuradoria Fiscal do Estado, ver nota no 3.

24 Segundo o Regimento Interno do Conselho, das decisões não unânimes cabia pedido de reconsideração, interposto no prazo de 15 dias, pela parte vencida. 
a 5/51 - CEC ${ }^{25}$ - somente aconteceu no dia 19/09/1951, ${ }^{26}$ sob a presidência de Moacyr Dornelles, tendo como conselheiros: Manoel Marques Leite, César Couto e Gervásio Kramer da Luz, representantes da Fazenda Pública Estadual; Arnaldo Reinert, representante da FEDERASUL e Sebastião Montigni da Silva, representante da FIERGS. O Procurador Fiscal presente foi Luiz Moretti e o Secretário (interino) Alberto de los Santos. ${ }^{27}$

\subsection{Tribunal Administrativo de Recursos Fiscais, antes da Vigência da Lei $n^{0} 6.537 / 73^{28}$}

A denominação - Tribunal Administrativo de Recursos Fiscais - foi determinada em 23.01.59, pelo art. $22^{29}$ da Lei (RS) $n^{0} 3.694,{ }^{30}$ de 6 de janeiro de 1959, que entrou em vigor na data de sua publicação (Rio Grande do Sul, 1959).

Quando da alteração da denominação (em 23.01.59), o Tribunal estava instalado no prédio $\mathrm{n}^{\circ} 712$ da Rua Duque de Caxias, onde funcionou até 26.05.61, ${ }^{31}$ reiniciando as sessões de julgamento, em 21.06.61, ${ }^{32}$ no $n^{\circ} 1270$ (Edifício Torelly) da Rua dos Andradas, lá permanecendo até 25.11.92, quando passou para a atual sede, à Rua Andrade Neves, $n^{\circ} 106,7^{\circ}$ e $8^{\circ}$ andares, nessa Capital.

O Tribunal tinha competência para julgar em segunda e última instância administrativa os litígios

25 CEC - Conselho Estadual de Contribuintes.

26 Já com as alterações introduzidas na Lei $n^{\circ}$ 973/50, pela Lei $n^{\circ} 1.378$, de 27 de dezembro de 1950.

27 A composição do Conselho passou a aparecer completa a partir da sessão de 30.10.51, que foi a seguinte: Presidente: Moacyr Dornelles; Conselheiros: Manoel Marques Leite, César Couto e Gervásio Kramer da Luz, representantes da Fazenda Pública Estadual; Arnaldo Reinert, representante da FEDERASUL; Sebastião Montigni da Silva, representante da FIERGS e Francisco Garcia de Garcia, representante da FARSUL. Presente o Procurador Fiscal Luiz Moretti.

28 Até 26.02.73.

29 "Art. 22 - De conformidade com o que estabelece o art. 241 da Constituição Estadual, é competente para julgamento dos processos fiscais de que trata o art. 43 em segunda e última instância, na esfera administrativa, o Tribunal Administrativo de Recursos Fiscais". Art. 43 - todas as questões a que se refere o art. $1^{\circ}$, exceto equidade e inconstitucionalidade.

30 A Lei $n^{\circ} 3.694 / 59$ tinha como ementa: "Dispõe sobre as penalidades e processo fiscais, na esfera administrativa e dá outras providências" (Rio Grande do Sul, 1959).

31 Data da última sessão registrada no n 712 da Rua Duque de Caxias.

32 Data da primeira sessão registrada no nº 1270 da Rua dos Andradas. 
suscitados entre a Fazenda Estadual e os contribuintes, versando, no todo ou em parte, sobre:

a) a instituição, a incidência, o lançamento, a arrecadação, a natureza ou quantum da obrigação tributária;

b) isenção e redução ou restituição de tributos;

c) aplicação e interpretação de leis e regulamentos fiscais em geral ${ }^{33}$ (Rio Grande do Sul, 1959).

Embora a competência para decidir sobre todas as questões relativas à matéria acima tenha sido plena, não foi autorizado o julgamento por equidade, nem o exame da inconstitucionalidade de norma.

O Tribunal compunha-se de sete membros:

a) um Presidente e seus dois suplentes (um $1^{\circ}$ Vice-Presidente e um $2^{\circ}$ VicePresidente), nomeados (e demissíveis) livremente pelo Governador do Estado, dentre bacharéis em Direito de reconhecida capacidade, de indiscutível idoneidade e equidistantes dos interesses dos contribuintes e do Fisco;

b) três Juízes representantes do Fisco, ${ }^{34}$ e seus suplentes, nomeados para um mandato de dois anos pelo
Governador, mediante indicação do Secretário da Fazenda, dentre funcionários da Secretaria da Fazenda de reconhecida competência em matéria de Direito Tributário e aproveitadas suas especializações.

c) três Juízes representantes dos contribuintes (em número igual ao de representantes do Fisco) e seus respectivos suplentes, nomeados para um mandato de dois anos pelo Governador do Estado, mediante indicação em lista quádrupla (no mínimo), respectivamente, pela Federação das Associações Comerciais do Rio Grande do Sul, pela Federação das Indústrias do Rio Grande do Sul e pela Federação das Associações Rurais do Rio Grande do Sul.

Junto ao Tribunal oficiavam, em conjunto ou separadamente, dois Representantes da Fazenda Pública Estadual (e um suplente), de livre designação e dispensa pelo Secretário da Fazenda, dentre os Procuradores Fiscais e funcionários da Secretaria da Fazenda, bacharéis em Ciências Jurídicas e Sociais, de reconhecida competência e idoneidade e aproveitadas as suas especializações, com as seguintes atribuições e prerrogativas:

a) ter vista de todos os processos, antes da distribuição aos relatores; usar da

33 Art. $1^{\circ}$ da Lei n ${ }^{\circ} 3.694 / 59$.

34 Enquanto servissem no TARF, ficavam dispensados de suas funções ordinárias, não podendo exercer qualquer outra comissão, exceto para estudo ou elaboração de trabalho técnico ou científico. Mantinham todas as vantagens do cargo de origem, além da gratificação por sessão a que comparecessem (até 15 sessões por mês). 
palavra, se lhe parecesse conveniente, por ocasião do julgamento;

b) pedir reconsideração, sempre que a decisão não tendo sido unânime, lhe parecesse contrária à prova dos autos ou à lei que regia o caso;

c) levar ao conhecimento do Secretário da Fazenda qualquer inobservância das disposições da lei ou irregularidades ocorridas na primeira instância.

A primeira sessão de julgamento, ${ }^{35}$ com a nova denominação, ocorreu em 27 de janeiro de $1959 .{ }^{36}$ O Tribunal esteve composto pelos Juízes: Jonas Cunha de Carvalhosa, representante da FEDERASUL; Antônio Cândido Silveira Pires, representante da FARSUL; Hugo Berta, representante da FIERGS e Joaquim Soter, Gervásio
Kramer da Luz e Mário Lucena Borges, ${ }^{37}$ representantes da Fazenda, que participaram do julgamento de 27 recursos $^{38}$ todos de ofício, sob a presidência de Gervásio Kramer da $\operatorname{Luz}^{39}$ (na condição de presidente substituto, na ausência do titular Carlos Alberto Leão dos Reis). Atuou como Representante da Fazenda junto ao Tribunal o Procurador Fiscal Plínio Vicente Medaglia.

\section{CONFIGURAÇÃO ATUAL $^{40}$ DO TRIBUNAL ADMINISTRATIVO DE RECURSOS FISCAIS (TARF)}

Sobre a configuração atual do Tribunal Administrativo de Recursos

35 O primeiro feito julgado foi o recurso de ofício no 951/58 - CEC, de decisão que havia deferido pedido de "isenção condicionada", em que era recorrida a Sociedade de Literatura e Beneficiência (sic) de Santo Ângelo. O TARF deu provimento ao recurso, para reconhecer a imunidade, visto comprovadamente, tratar-se de "Entidade de Educação e Assistência Social”. A decisão foi consubstanciada no Acórdão nº 95/59. 36 Seguiram-se sessões nos dias 28 e 29.01.59, com a mesma composição.

37 Mário Lucena Borges não assinou o acórdão, provavelmente não participou do julgamento para manter a paridade entre as representações, já que os juízes presentes eram em número de cinco (quatro votantes).

38 Acórdãos de nºs 95/59 a 121/59.

39 Segundo os registros em acórdãos da época, a composição plena do Tribunal era a seguinte: Presidente: Carlos Alberto Leão dos Reis (Vice-Presidente: Ruy Rodrigo Brasileiro de Azambuja, tomou posse em 03.02.59) e Juízes: Gervásio Kramer da Luz, Joaquim Soter e Mário Lucena Borges, representantes da Fazenda; Hugo Berta, representante da FIERGS; Jonas Cunha de Carvalhosa, representante da FEDERASUL e Antônio Cândido Silveira Pires, representante da FARSUL. O Representante da Fazenda junto ao Tribunal era Plínio Vicente Medaglia.

40 A partir da vigência da Lei n 6.537/73, ou seja, a partir de 27.02.73. 
Fiscais, cabe conhecer: sua criação, competência, composição, atribuições do Presidente do Tribunal, atribuições do Secretário-Geral do Tribunal, configuração das Câmaras do Tribunal, competência das Câmaras, atribuições dos Presidentes das Câmaras, atribuições dos Juízes, impedimentos, atribuições dos Secretários das Câmaras, defesa da Fazenda Pública Estadual junto ao TARF, serviços auxiliares, avocação de julgamento pelo Secretário de Estado da Fazenda, súmulas de jurisprudência do TARF, Regimento Interno e atuação do sujeito passivo junto ao Tribunal (partes, representantes e procuradores).

\subsection{Generalidades}

O Tribunal Administrativo de Recursos Fiscais (TARF) foi criado pela Lei ${ }^{\circ} 3.694,{ }^{41}$ de 16 de janeiro de
1959, ${ }^{42}$ em substituição ao Conselho Estadual de Contribuintes (CEC); atualmente é regido pela Lei ${ }^{\circ} 6.537,{ }^{43}$ de 27 de fevereiro de 1973; tem sede em Porto Alegre, à Rua Andrade Neves, $n^{0} 106,7^{\circ}$ e $8^{\circ}$ andares, ${ }^{44}$ e jurisdição em todo o território do Estado do Rio Grande do Sul. É órgão colegiado, que julga em segunda e última instância administrativa os litígios de natureza tributária, suscitados entre a Fazenda Pública Estadual e os sujeitos passivos de imposição tributária da competência do Estado do Rio Grande do Sul. ${ }^{45}$

\subsection{Competência}

\section{Compete $^{46}$ ao Tribunal Pleno:}

a) julgar os recursos extraordinários e os pedidos de esclarecimento interpostos de suas próprias decisões;

41 Com suporte no art. 241 da Constituição do Estado do Rio Grande do Sul, de 1945 (Rio Grande do Sul, 1945).

42 Publicada no DOE de 23.01.59 (data da vigência) (Rio Grande do Sul, 1959).

43 É regido pela Lei (RS) $n^{\circ} 6.537 / 73$ (Rio Grande do Sul, 1973), com as alterações introduzidas pelas Leis $\mathrm{n}^{\circ} \mathrm{s}$ 8.694/88; 9.481/91; 9.764/92; 10.582/95 e 11.475/00 (Rio Grande do Sul, 1988, 1991, 1992, 1995, 2000) e pelo seu Regimento Interno Resolução TARF no 001/2002 (Rio Grande do Sul, 2002).

44 Desde a adoção da denominação "Tribunal Administrativo de Recursos Fiscais", esteve instalado no prédio $\mathrm{n}^{\circ} 712$ da Rua Duque de Caxias, onde funcionou até 26.05.61, reiniciando as sessões de julgamento, em 21.06.61, no $6^{\circ}$ andar do $n^{\circ} 1270$ (Edifício Torelly) da Rua dos Andradas, onde permaneceu até 25.11.92, quando foi transferido para o endereço atual.

45 Mediante convênios firmados entre o Estado e os Municípios, as autoridades administrativas estaduais podem ser incumbidas, também, da apreciação e do julgamento de questões suscitadas entre a respectiva Fazenda Pública Municipal e seus contribuintes. 46 Quanto à competência do órgão julgador de segunda instância administrativa. Deve-se levar em conta que a discussão de matéria tributária na esfera administrativa 
b) propor ao Secretário de Estado da Fazenda a redução ou dispensa, por equidade, ${ }^{47}$ de multas impostas ao sujeito passivo, nos termos da lei;

c) distribuir os juízes por Câmaras, respeitada a paridade de representação;

d) propor às autoridades competentes medidas de racionalização e aperfeiçoamento da legislação tributária estadual;

e) aprovar súmulas da jurisprudência do Tribunal;

f) aprovar e promover alterações no seu Regimento Interno; ${ }^{48}$

g) resolver questões administrativas quando propostas pelo presidente ou suscitadas por um dos juízes;

h) apreciar a justificação das faltas do presidente e dos juízes às respectivas reuniões ou sessões; i) estabelecer dia e horário para as reuniões;

j) conceder férias e licenças ao presidente do Tribunal;

k) instituir e conferir distinções honoríficas;

l) praticar os demais atos não especificados na competência das Câmaras;

m) resolver dúvidas e omissões na aplicação do Regimento Interno do Tribunal.

\subsection{Composição}

O Tribunal Administrativo de Recursos Fiscais (TARF) compõe-se de oito Juízes, ${ }^{49}$ com seus respectivos

decorre de opção do sujeito passivo de exigência tributária, pois esse pode levar a demanda diretamente ao Poder Judiciário. Porém, eleita a opção administrativa, o processo deverá ser constituído e conduzido na forma da legislação específica. Os órgãos Julgadores de Segunda Instância Administrativa Tributária, obviamente, têm competência para reexaminar, em grau de recurso, decisões da primeira instância administrativa tributária, exceto casos de avocação previstos em lei, além de suas próprias decisões, em casos especiais previstos na legislação. Cada Unidade da Federação ao fixar a competência em razão da matéria e do território usa de linguagem própria, condicionando sempre, no contencioso, ao exame prévio por outro órgão administrativo tributário, por ela definido.

47 Segundo o art. 138 da Lei $n^{\circ}$ 6.537/73, o Secretário de Estado da Fazenda, por proposição das autoridades julgadoras ou quando avocar julgamento (por não haver julgamento no Tribunal pleno ou em Câmara) poderá, atendendo às características pessoais ou materiais do caso:

a) reduzir ou dispensar, por equidade, multas por infrações de natureza formal;

b) reduzir, por equidade, as multas por infrações tributárias de natureza material, até o grau correspondente às privilegiadas, desde que não tenha havido dolo, fraude ou simulação.

48 O Regimento Interno deve conter, além de outras disposições, a composição das Câmaras, assegurando a participação, em cada uma delas, de dois juízes representantes da Fazenda.

49 Até 31.08.88, compunha-se de seis juízes, um presidente, um primeiro vicepresidente e um segundo vice-presidente. No caso de funcionamento da Câmara Suplementar a composição do tribunal pleno compreenderá os juízes integrantes desta, perfazendo um total de 12 juízes. 
suplentes,$^{50}$ com mandato de quatro ${ }^{51}$ anos, admitida uma recondução; ${ }^{52}$ um Presidente; ${ }^{53}$ um Primeiro VicePresidente; um Segundo VicePresidente e um Terceiro VicePresidente, todos nomeados pelo Secretário de Estado da Fazenda, dentre bacharéis em Ciências Jurídicas e Sociais. Os quatro Juízes que representam a Fazenda Estadual e seus suplentes são escolhidos entre Fiscais De Tributos Estaduais ${ }^{54}$ e os quatro Juízes que representam os contribuintes e seus respectivos suplentes $^{55}$ serão indicados, em listas de seis $^{56}$ nomes, no mínimo, pela Federação das Associações Comerciais do Rio Grande do Sul FEDERASUL, pela Federação das Indústrias do Estado do Rio Grande do Sul - FIERGS, pela Federação da Agricultura do Estado do Rio Grande do Sul - FARSUL e pela Organização das Cooperativas do Estado do Rio Grande do Sul - OCERGS, ${ }^{57}$ respectivamente.

50 No caso de impedimento ou de impossibilidade de comparecimento a qualquer sessão, os Juízes providenciarão, antecipadamente, junto à Secretaria do TARF, no comparecimento do respectivo suplente.

51 Até a vigência da Lei $n^{\circ}$ 11.475/00 (Rrio Grande do Sul, 2000), o mandato dos Juízes, e de seus suplentes, era de dois anos, 'admitida a recondução por igual período'. O STF, em liminar, na Adi nº 2405 (em andamento) suspendeu a redação introduzida no art. 98 da Lei $n^{\circ} 6.537 / 73$, pelo inciso IV do art. $1^{\circ}$ da Lei $n^{0} 11.475 / 00$, que aumentou de dois para quatro anos, o mandato dos Juízes. Em razão da liminar e enquanto ela estiver em vigor o mandato é de dois anos.

52 Os Juízes permanecerão no exercício de suas funções até a posse dos novos titulares, mesmo após o término de seus mandatos.

53 O Presidente do TARF, o Presidente da Segunda Câmara, o Presidente da Câmara Suplementar e o Vice- Presidente, que exercer a Presidência do TARF ou a de qualquer das Câmaras, por dez dias consecutivos, além da gratificação por sessão, percebem, a título de representação, acréscimo de 50\% sobre aquela.

54 Enquanto estiverem em exercício no TARF ou em qualquer de suas Câmaras, percebem, além das gratificações a que se refere o artigo 102, todas as vantagens de seus cargos, como se no seu exercício estivessem e ficam dispensados do desempenho de suas funções ordinárias, não podendo exercer cumulativamente qualquer outra comissão, exceto para estudo ou elaboração de trabalho técnico-científico.

55 No mínimo dois e no máximo cinco suplentes para cada Juiz.

56 Até 26.11.92, a lista devia conter 4 nomes, no mínimo.

57 A participação da Organização das Cooperativas do Estado do Rio Grande do Sul - OCERGS, na composição do TARF, foi determinada pelo art. $1^{\circ}, \mathrm{XXV}$, da Lei $\mathrm{n}^{\circ}$ 8.694/88 (RIO GRANDE DO SUL, 1988). A posse da sua primeira representação ocorreu em 8/9/88, quando prestaram compromisso Pery de Quadros Marzullo, como 
O Presidente e os Vice-Presidentes são de livre escolha e demissão do Secretário da Fazenda, dentre bacharéis em Ciências Jurídicas e Sociais, de reconhecida competência e idoneidade e equidistantes dos interesses da Fazenda Estadual e dos contribuintes.

O Plenário do TARF funciona com a presença mínima de dois terços dos seus membros ${ }^{58}$ e as Câmaras com a sua totalidade, assegurada a representação paritária, e as decisões são tomadas por maioria de votos, sendo que os respectivos presidentes só têm voto de desempate.

A composição plenária atual do Tribunal é a seguinte: Presidente: Gentil André Olsson; Primeiro Vice-
Presidente: Ênio Aurélio Lopes Fraga; Segundo Vice-Presidente: Fernando Dornelles Moretti; Secretário-Geral: ${ }^{59}$ Jorge Luiz Brito Wincher; Juízes Representantes da Fazenda Estadual: ${ }^{60}$ Fábio Weber Nowaczyk, Ivori Jorge da Rosa Machado, Luiz Antônio Bins e Nelson Reschke; Juízes Representantes dos Contribuintes: Antônio José de Mello Widholzer - FIERGS, ${ }^{61}$ Ademir Costa Monteiro - FARSUL, ${ }^{62}$ Mário De Conto-OCERGS ${ }^{63}$ e Dione Tertuliano Tarasconi - FEDERASUL. ${ }^{64}$

\subsection{Atribuições do Presidente do Tribunal}

Compete ao Presidente do Tribunal, ${ }^{65}$ além de presidir as sessões

Juiz Titular (de 08.09.88 a 06.07.93) e Saleti Aimê Lucca, como suplente (de 08.09.88 a 23.03.93).

58 Os membros do TARF têm direito à gratificação prevista em Lei, por sessão a que compareçam, até o máximo, por mês, de trinta por Câmara, e de dez pelo plenário, salvo necessidade de agilização dos julgamentos, caso em que o presidente do TARF autoriza que o limite máximo de sessões seja ampliado para até cinquenta sessões, por mês, em cada Câmara.

59 Os Secretários das Câmaras e do Plenário perceberão o equivalente a um quarto do valor da gratificação paga aos juízes por sessão que secretariem.

60 Os atuais suplentes da representação da Fazenda são: Luciano Coelho Guimarães e Rodrigo Maciel de Souza.

61 Juiz Suplente da FIERGS: Cândido Bortolini.

62 Juiz Suplente da FARSUL: Cilon da Silva Santos.

63 Juiz Suplente da OCERGS: Nielon José Meireles Escouto.

64 Juiz Suplente da FEDERASUL: Fúlvio Araújo Santos.

65 No impedimento ocasional e simultâneo do Presidente e dos Vice-Presidentes, exerce a Presidência do TARF o mais antigo dos Juízes presentes ou, sendo iguais em antiguidade, dentre eles o mais idoso. 
plenárias do Tribunal e as sessões da Primeira Câmara:

a) exercer a direção do órgão;

b) representar o Tribunal;

c) aplicar sanções administrativas aos servidores do Tribunal, na forma da lei;

d) dar posse aos membros do Tribunal, recebendo os respectivos compromissos;

e) conceder férias e licenças aos servidores do Tribunal, bem como apreciar a justificação de suas faltas; $; 6$

f) solicitar ao Secretário de Estado da Fazenda os recursos materiais e humanos necessários ao regular funcionamento do Tribunal;

g) conceder férias ${ }^{67}$ e licenças aos juízes e vice-presidentes;

h) expedir instruções e ordens de serviço;

i) atestar a efetividade dos juízes, dos defensores da Fazenda e dos servidores; j) apresentar ao Secretário de Estado da Fazenda, anualmente, até 31 de janeiro, relatório das atividades do Tribunal;

1) oficiar ao Secretário de Estado da Fazenda, com antecedência mínima de 30 dias, comunicando o término do mandato dos membros do Tribunal e seus suplentes;

m) aprovar a realização de eventos de caráter cultural, técnico ou jurídico, de interesse do Tribunal;

n) indeferir liminarmente, após a ouvida da Defensoria da Fazenda, os recursos não previstos na legislação pertinente e no Regimento Interno do Tribunal;

o) ordenar por despacho a cobrança dos autos com prazo vencido; 68

p) cumprir e fazer cumprir o Regimento Interno do Tribunal;

q) comunicar, ao Secretário da Fazenda, a falta de comparecimento, sem motivo justificado, do Defensor da Fazenda e do suplente, a três sessões consecutivas.

66 A falta de comparecimento de qualquer Juiz a cinco sessões consecutivas ou a dez alternadas, por ano de mandato, importará, salvo motivo plenamente justificado, em renúncia tácita, devendo o Presidente comunicar o fato ao Secretário da Fazenda, para o efeito de preenchimento da vaga. Somente são consideradas plenamente justificadas, salvo motivo de força maior, as faltas comunicadas antecipadamente à instalação da reunião.

67 Os Membros do TARF têm direito a um período de férias anuais de trinta dias consecutivos, sem prejuízo de suas vantagens, inclusive os Juízes Suplentes que exercerem as funções em caráter efetivo.

68 O não atendimento, pelos Juízes, da cobrança dos autos com prazo vencido, em dez dias, implica perda da gratificação por comparecimento às sessões, enquanto não atendida a ordem (RITARF). O Juiz que deixar de cumprir despacho da presidência, ordenando a cobrança de autos com prazo vencido, perderá a gratificação por comparecimento às sessões, enquanto não atender à determinação (Lei $n^{\circ} 6.537 / 73$ ) (Rio Grande do Sul, 1973). 


\subsection{Atribuições do Secretário- Geral do Tribunal}

Ao secretário-geral, incumbe:

a) secretariar os trabalhos do Pleno;

b) assistir às sessões, redigir e ler as respectivas atas;

c) providenciar a pauta das sessões do Pleno;

d) encaminhar, para publicação no Diário Oficial do Estado, as pautas do Pleno e das Câmaras, e os demais atos de interesse do Tribunal;

e) subscrever as certidões autorizadas pelo presidente e pelos vicepresidentes;

f) fornecer os dados necessários ao relatório anual do Tribunal;

g) fazer a previsão dos recursos materiais e humanos necessários aos serviços administrativos do Tribunal e supervisionar a sua execução;

h) determinar as tarefas a serem executadas pelos servidores em exercício no Tribunal;

i) praticar os demais atos determinados pelo presidente do Tribunal.

\subsection{Configuração das}

\section{Câmaras do Tribunal}

Integram o Tribunal duas câmaras permanentes.

\subsubsection{Primeira Câmara}

APrimeira Câmara, que épresidida pelo Presidente do TARF, é composta por dois dos Juízes representantes da Fazenda e dois dos Juízes representantes dos contribuintes;
Atualmente, a Primeira Câmara está assim constituída: Gentil André Olsson, Presidente; Ivori Jorge da Rosa Machado e Nelson Reschke, Juízes titulares, representantes da Fazenda; Antônio José de Mello Widholzer, Juiz titular representante da FIERGS (Juiz suplente: Cândido Bortolini) e Mário de Conto, Juiz titular representante da OCERGS (Juiz suplente: Nielon José Meirelles Escouto). A Secretária da Câmara é Ledi Maria Rossatto.

Junto à Primeira Câmara, atuam os Defensores da Fazenda Galdino Bollis e Roberto Camargo da Silva.

\subsubsection{Segunda Câmara}

ASegunda Câmara, que é presidida pelo primeiro vice-presidente do TARF, é composta por dois dos juízes representantes da fazenda e dois juízes representantes dos contribuintes.

Atualmente, a Segunda Câmara está assim constituída: Ênio Aurélio Lopes Fraga, Presidente; Fábio Weber Nowaczyk e Luiz Antônio Bins, Juízes titulares representantes da Fazenda; Ademir Costa Monteiro, Juiz titular representante da FARSUL (Juiz suplente: Cilon da Silva Santos) e Dione Tertuliano Tarasconi, Juiz titular representante da FEDERASUL (Juiz suplente: Fúlvio Araújo Santos). O Secretário da Câmara é Agostinho Toniolo.

Junto à Segunda Câmara, atuam os Defensores da Fazenda Abel 
Henrique Ferreira e Marcolina Maria Gerevini Dias.

\subsubsection{Câmara Suplementar}

Mediante proposta do Presidente Do TARF $^{69}$ ao Secretário de Estado da Fazenda, este poderá autorizar o funcionamento de uma Câmara Suplementar, ${ }^{70}$ que terá caráter transitório, respeitado o prazo máximo de dois anos. A Câmara Suplementar será presidida pelo Segundo VicePresidente do TARF e será composta respeitando as mesmas regras aplicadas às permanentes, podendo ser integrada pelos membros suplentes do TARF ou por Juízes nomeados $^{71}$ e Defensores designados pelo Secretário de Estado da Fazenda, na forma prevista para os membros das câmaras permanentes. ${ }^{72}$

\subsection{Competência das Câmaras}

Compete às Câmaras:

a) julgar recursos voluntários, recursos de ofício, pedidos de reconsideração e pedidos de esclarecimento, interpostos de suas próprias decisões; pedidos de restituição de tributo, multa e seus acréscimos legais; pedidos de reconhecimento de isenção e outras matérias que lhe forem atribuídas por lei; b) propor ao Secretário de Estado da Fazenda a redução ou dispensa, por equidade, de multas impostas ao sujeito passivo, nos termos da lei;

c) apreciar a justificação das faltas do seu presidente e dos seus juízes às respectivas reuniões e sessões.

\subsection{Atribuições dos Presidentes das Câmaras}

Aos Presidentes das Câmaras, ${ }^{73}$ incumbe:

69 Pela Lei no 9.764, de 26 de novembro de 1992, foi criada Câmara Suplementar, que funcionou de 28.09.94 a 28.08.98.

70 A Lei no 10.582/95 (Rio Grande do Sul, 1995) possibilitou criação de uma Segunda Câmara Suplementar, pelo prazo máximo de um ano, presidida pelo Terceiro VicePresidente do TARF, que observadas, no mais, as regras de criação e composição da Câmara Suplementar, foi instalada em 09.05.96 e funcionou de 6/96 a 5/97.

71 Os contribuintes serão representados, na Câmara Suplementar, por Juízes indicados por duas das entidades acima referidas, que serão sorteadas pelo Pleno, os quais terão como suplentes os indicados pelas outras duas entidades.

72 Cada uma das Câmaras terá um Secretário e o Pleno um Secretário Geral.

73 A Presidência da Primeira Câmara é exercida pelo Presidente do TARF, cabendo ao Primeiro Vice-Presidente o exercício da Presidência da Segunda Câmara. O Presidente do Tribunal Pleno e os Presidentes das Câmaras estão sujeitos aos impedimentos aplicados aos Juízes. 

a) presidir as sessões, resolver as questões de ordem e apurar as votações;
b) proferir voto de desempate; ${ }^{74}$
c) designar relator substituto;
d) convocar suplente de juiz; ${ }^{75}$
e) convocar reuniões extraordinárias;
f) distribuir os processos de acordo com o estabelecido no Regimento Interno do Tribunal;
g) requisitar as diligências aprovadas nas sessões;

h) aprovar a pauta das sessões;

i) assinar as atas das sessões;

j) assinar os acórdãos, juntamente com o relator;

l) determinar a baixa de autos de recursos definitivamente decididos;

$\mathrm{m})$ determinar à secretaria respectiva a elaboração, a cada 30 dias, de relação dos autos com prazo vencido; n) determinar a cobrança de autos com prazo vencido, de ofício ou a requerimento das partes;

o) autorizar o fornecimento de cópias reprográficas ou de certidões, quando requeridas;

p) exercer as demais funções de corregedoria.

\subsection{Atribuições dos Juízes}

Aos juízes incumbe:

a) relatar os processos que lhes forem distribuídos;

b) proferir voto, que deverá ser deduzido por escrito sempre que for o primeiro divergente da decisão majoritária;

c) redigir os acórdãos de processos em que for relator ou cuja redação lhe for cometida;

d) substituir, na presidência das sessões, o presidente do Pleno ou da Câmara, quando ausentes seus substitutos legais;

e) propor, em sessão, diligências que entender necessárias à instrução processual;

f) solicitar vista de processo;

g) declarar-se impedido de participar de decisão, nos casos previstos no Regimento Interno do Tribunal;

h) apresentar sugestões de interesse do Tribunal;

i) submeter ao Pleno qualquer irregularidade de que tenha conhecimento relativamente aos serviços do Tribunal;

74 O Presidente do TARF e os Presidentes das Câmaras têm apenas o voto de desempate. 75 Segundo o Regimento Interno, a convocação, quando feita para suprir ausência em Câmara de titular para reunião completa, constará de escala rotativa permanente controlada pela Secretaria Geral segundo critério de antiguidade ininterrupta na suplência, podendo deixar de ser convocado, sem obrigatoriedade de compensação posterior, aquele que, excedendo o prazo de 10 dias para a lavratura de acórdão, estiver, a critério do presidente, sobrecarregado na entrega de acórdãos à Secretaria. 
j) deliberar sobre matéria administrativa.

\subsection{Impedimentos}

Os membros do TARF estão impedidos $^{76}$ de discutir e votar nos processos:

a) de seu interesse pessoal ou de seus parentes até o terceiro grau, inclusive;

b) de interesse da empresa de que são diretores, administradores, sócios, acionistas, membros do Conselho Fiscal, assessores ou a que estejam ligados por vínculo profissional;

c) em que houverem proferido decisão sobre o mérito, na primeira instância.

Segundo o Regimento Interno do TARF, os juízes podem, ainda, darse por impedidos de atuar em feitos, por motivos de foro íntimo, mediante declaração encaminhada, por escrito, ao presidente da Câmara ou do Pleno, conforme o caso, em tempo que permita a convocação de suplente.

\subsection{Atribuições dos Secretários das Câmaras}

Aos secretários das Câmaras, incumbe:

a) secretariar os trabalhos da respectiva Câmara;

b) assistir às sessões, redigir e ler as respectivas atas;

c) providenciar a pauta das sessões e encaminhá-la ao secretário-geral para publicação no Diário Oficial do Estado; d) organizar e remeter ao secretário-

76 Imparcialidade do Juízo. É pressuposto processual de validade da decisão que o julgador (juiz, conselheiro ou vogal) que a profira ou dela participe seja imparcial, que não tenha motivação para atuar no interesse de uma das partes, pois o interesse que deve prevalecer é o da justiça. Objetivamente tem-se como imparcial aquele julgador que não se enquadra em nenhum dos motivos de impedimento ou de suspeição definidos na legislação própria, tais como:

a) interesse pessoal no feito (DF, RS, SC, RO, MS e AL);

b) interesse de parentes, consanguíneos ou não, até o segundo grau inclusive (DF e AL); terceiro grau inclusive (RS, RO, SE, SC e GO);

c) interesse de sociedade de que faça, ou tenha feito, parte como sócio, advogado, membro da diretoria ou conselho (DF, RS, SC, AL e GO), sob vínculo permanente (RO);

d) houver proferido decisão de mérito ou emitido parecer no processo (DF, RS e GO);

e) ter sido autor do procedimento fiscal (GO).

Alguns regimentos estabelecem normas procedimentais da "Exceção de Suspeição" (DF, MS e PE) no caso de não haver sido espontaneamente declarado o impedimento pelo julgador. 
geral os atos da respectiva Câmara, a serem publicados no Diário Oficial; e) executar todas as tarefas necessárias ao pleno funcionamento das Câmaras a que servirem, de acordo com as determinações do seu presidente.

\subsection{Defesa da Fazenda Pública Estadual junto ao TARF}

Cabe ao "defensor" o exame inicial do recurso interposto pela parte sucumbente e a consequente manifestação escrita (contra-razões ou parecer), que deve compreender a análise das condições de admissibilidade do recurso e do mérito do pedido que ele contém.

Com a instauração do processo, emerge como objeto da atividade jurisdicional o exame de duas relações jurídicas; uma, que é a lide propriamente dita, entre o impugnante e o Estado, este na condição de pretendente do crédito tributário, que é o objeto último do processo; a outra é a relação processual que se estabelece, desde o momento inicial, entre o sujeito passivo da obrigação tributária e o Estado, este na condição de prestador da jurisdição.

A representação da Fazenda atua tanto no plano da relação de direito material, quanto no da relação jurídica processual, quando ess apresentar algum vício, irregularidade ou omissão que a torne defeituosa ou ilegítima.

Compete-lhe, portanto, antes de discutir o mérito da causa, alegar como preliminares, todas as arguições admissíveis.

O juízo de admissibilidade tem por finalidade a aferição do preenchimento dos requisitos formais necessários para que o processo se constitua e tenha seguimento, atingindo, ao final, o seu objetivo, que é a solução da lide.

Segundo a legislação do Estado do Rio Grande do Sul, com o objetivo de preservar os interesses do Erário

Evidentemente que, ao eleger critérios objetivos de impedimento, o legislador não teve por escopo induzir a ideia de que quem julga em tais condições necessariamente é parcial. O principal motivo do impedimento, além de evitar o constrangimento íntimo do juiz em ter que interferir em decisão que ele ou pessoas próximas tenham interesse, é o de preservar a imagem externa do julgador e do próprio juízo, pois não é suficiente que eles sejam imparciais, é importante que pareçam imparciais às partes.

77 No País, junto aos órgãos colegiados estaduais de julgamento do contencioso tributário administrativo, atuam, como defensores dos interesses do erário público, Procuradores do Estado (CE, SE, PE, MS e DF), Procuradores Fiscais (MG, BA e SC) e "Representantes da Fazenda", "Representantes Fiscais" ou "Defensores da Fazenda" (RJ, GO, PR, SP, RO e RS). Os primeiros provêm dos quadros da respectiva Procuradoria do Estado e o segundo grupo é oriundo dos quadros da Procuradoria Fiscal do respectivo Estado. Os demais,são recrutados entre funcionários dos quadros da 
Estadual, ${ }^{77}$ promover sua ampla defesa e estabelecer o contraditório, oficiam junto ao Tribunal e suas Câmaras, em conjunto ou separadamente, quatro $^{78}$ Defensores da Fazenda Pública Estadual, ${ }^{79}$ e seus suplentes, ${ }^{80}$ designados (e demissíveis ad nutum) pelo Secretário de Estado da Fazenda, ${ }^{81}$ dentre Fiscais de Tributos Estaduais, bacharéis em Ciências Jurídicas e Sociais, com as seguintes atribuições: ${ }^{82}$

a) ter vista e falar em todos os processos, antes de distribuídos aos relatores; b) usar da palavra nas sessões de julgamento, na forma regimental;

c) solicitar a realização de diligências;

d) requerer à Presidência do TARF ou das Câmaras, conforme o caso, a cobrança de autos com prazo vencido;

e) prestar esclarecimentos quando solicitados pelos juízes;

f) pedir esclarecimento das decisões do Plenário ou das Câmaras, entendidas omissas, contraditórias ou obscuras;

g) interpor, ao Plenário do TARF, recurso extraordinário das decisões das Câmaras proferidas com o voto

Secretaria da Fazenda ou Finanças (geralmente do quadro de "Fiscais", ou equivalente, ou do Departamento Jurídico da Secretaria da Fazenda) e designados para a função, pelo respectivo Secretário de Estado, por prazo indeterminado, e por ele dispensáveis "ad nutum”. Em alguns dos Estados, como o Rio de Grande do Sul, a função é privativa de "Agente Fiscal do Tesouro do Estado (anteriormente, Fiscal de Tributos Estaduais), bacharel em Ciências Jurídicas e Sociais”.

78 A atual Defensoria da Fazenda junto ao TARF está assim composta: Abel Henrique Ferreira, Galdino Bollis, Marcolina Maria Gerevini Dias e Roberto Camargo da Silva.

79 Enquanto estiverem em exercício no TARF ou em qualquer de suas Câmaras, percebem, além das gratificações recebidas pelos Juízes, todas as vantagens de seus cargos, como se no seu exercício estivessem e ficam dispensados do desempenho de suas funções ordinárias, não podendo exercer cumulativamente qualquer outra comissão, exceto para estudo ou elaboração de trabalho técnico-científico.

80 Em caso de acúmulo de serviço e por determinação expressa do Secretário de Estado da Fazenda, os suplentes poderão oficiar simultaneamente com os titulares.

81 Na hipótese de funcionamento da Câmara Suplementar, e pelo prazo respectivo, oficiarão mais dois Defensores da Fazenda, com dois suplentes, junto ao Plenário do TARF.

82 No País, as atribuições do "Defensor dos interesses da Fazenda" junto aos Conselhos (AC, AM, AP, AL, SE, SC, ES, TO, BA, GO, RR, MT, MG, PR, PB, RJ e RN); Tribunais (DF, MA, MS, PA, PE, RO, RS e SP); Contencioso (CE) ou Junta (AM), definidas na legislação das diversas Unidades da Federação, podem ser agrupadas em quatro áreas de atuação: 
de desempate de seu Presidente, quando entendê-las contrárias à legislação ou à evidência dos autos;

h) requisitar a qualquer repartição pública estadual as informações que julgarem necessárias ao esclarecimento de processo de que tenham vista, as quais lhe serão fornecidas com a maior brevidade;

i) comunicar ao Diretor do Departamento da Receita Pública Estadual quaisquer irregularidades verificadas na instrução dos processos sob sua defesa, em detrimento da Fazenda ou do contribuinte.

A ausência ${ }^{83}$ de Defensor da Fazenda às sessões não impedirá que o TARF, ou qualquer de suas Câmaras, delibere. Em caso de impedimento, o próprio Defensor da Fazenda deve providenciar no comparecimento do seu suplente.

\subsection{Serviços auxiliares}

O TARF ${ }^{84}$ conta, para a execução de seus serviços administrativos, além de funcionários do Quadro de Pessoal Efetivo da Secretaria da Fazenda, designados, mediante ato próprio, pelo titular da Pasta Fazendária, com pessoal contratado por empresas prestadoras de serviços e estagiários, todos subordinados diretamente ao Secretário-Geral do Tribunal.

I - Atuação, no interesse da Fazenda, nos recursos interpostos pelo sujeito passivo do crédito tributário;

II - Interposição dos recursos cabíveis, das decisões contrárias aos interesses da Fazenda (inclusive, procedimentos incidentais como “pedido de esclarecimento”), bem como acompanhamento e sustentação dos recursos de ofício;

III - Fiscalização da aplicação da legislação e prática de atos de instrução processual e correição;

IV - Fornecimento à administração fazendária de elementos de autocrítica e sugestões capazes de proporcionar a avaliação e adequação de seu sistema normativo e operacional de fiscalização e exação.

83 As férias e as Licenças dos Defensores da Fazenda são Concedidas pelo Secretário da Fazenda.

84 O Tribunal conta, atualmente, com sete Técnicos do Tesouro do Estado (Jorge Luiz Brito Wincher, Ledi Maria Rossatto, Agostinho Toniolo, Laudina Maria Foletto, João Carlos Ribeiro Noronha, Leandro Moraes Bersagui e Stela Maris de Albuquerque Fontoura), sete servidores contratados por empresas prestadoras de serviços e quatro vagas para estagiários. 


\subsection{Avocação de Julgamento pelo Secretário de Estado da Fazenda}

Se por falta de quorum, decorrente de ausência de Juízes representantes dos contribuintes e/ou da Organização das Cooperativas do Estado do Rio Grande do Sul, o Plenário do TARF ou qualquer de suas Câmaras deixarem de se reunir por cinco sessões consecutivas, o Secretário de Estado da Fazenda poderá avocar o julgamento dos processos pendentes, incluídos na pauta das sessões não realizadas, proferindo decisão irrecorrível na esfera administrativa. ${ }^{85}$

\subsection{Súmulas de Jurisprudência do TARF}

A condensação da jurisprudência predominante do Tribunal em súmulas ${ }^{86}$ far-se-á por proposta, de qualquer de seus integrantes, dirigida ao plenário, indicando o enunciado e instruída, pelo menos, com três decisões unânimes, de cada uma das Câmaras.

A proposta será apreciada em sessão realizada, pelo menos, sete dias após sua apresentação (com distribuição de cópia da proposição aos juízes) e, se aprovada por maioria absoluta de seus membros, entrará em vigor na data de sua publicação no Diário Oficial do Estado.

As súmulas do Tribunal serão numeradas sequencialmente e, quando aplicadas, dispensam maiores considerações a respeito da matéria.

Por proposta de qualquer dos integrantes do Tribunal o enunciado de súmula poderá ser alterado ou revogado, por maioria absoluta do Pleno, passando a produzir efeitos a partir da data de sua publicação no Diário Oficial do Estado.

\subsection{Regimento Interno}

Segundo a Lei $\mathrm{n}^{\circ}$ 6.537/73, o Regimento Interno do TARF deve conter, no mínimo (Rio Grande do Sul, 1973):

a) a distribuição proporcional dos processos a relatar, segundo a ordem cronológica da autuação;

b) a rigorosa igualdade de tratamento às partes;

c) publicação das pautas de julgamento no Diário Oficial do Estado, com quarenta e oito horas de antecedência, no mínimo;

d) direito de vista dos autos pelo sujeito passivo;

e) direito de defesa oral nos recursos; f) realização de três sessões semanais, no mínimo, para cada uma das câmaras e de duas mensais, no mínimo, para o plenário;

85 Norma introduzida na Lei $n^{\circ}$ 6.537/73, pelo art. $1^{\circ}$, XXVI, da Lei $N^{\circ}$ 8.694/88 (Rio Grande do Sul, 1988).

86 Atualmente, o Tribunal tem 19 súmulas em vigor. 
g) a composição e a competência das câmaras, e a competência do plenário; h) os requisitos essenciais de admissibilidade do recurso previsto no $\S 1^{\circ}$, do art. 63, da lei $\mathrm{n}^{\circ} 6.537 / 73$.

$\mathrm{O}$ atual Regimento Interno do TARF foi aprovado pela Resolução TARF $n^{\circ}$ 1/2002 (Rio Grande do Sul, 2002).

\subsection{A Atuação do Sujeito Passivo Junto ao Tribunal}

A intervenção do sujeito passivo far-se-á diretamente ou por intermé- dio de procurador, que deverá ser advogado inscrito na Ordem dos Advogados do Brasil.

As pessoas jurídicas são representadas por seus dirigentes legalmente constituídos.

Não produzirá efeito, a intervenção de dirigentes ou procuradores se, no ato, não for feita a prova de que os mesmos são detentores dos poderes de representação.

Independentemente de intimação, o sujeito passivo poderá ter vista dos autos processuais na repartição em que estejam tramitando.

\section{REFERÊNCIAS}

RIO GRANDE DO SUL. Constituição do Estado do Rio Grande do Sul. Porto Alegre: Assembleia Legislativa, 1945.

RIO GRANDE DO SUL. Lei $\mathrm{n}^{\circ}$ 3.694/59. Diário Oficial do Estado, Porto Alegre, 23 jan. 1959.

RIO GRANDE DO SUL. Lei $\mathrm{n}^{\circ}$ 6.537/73. Diário Oficial do Estado, Porto Alegre, 27 fev. 1973.

RIO GRANDE DO SUL. Lei n ${ }^{\circ}$ 8.694/88.

Diário Oficial do Estado, Porto Alegre, 18 jul. 1988.

RIO GRANDE DO SUL. Lei n ${ }^{\circ}$ 9.481/91.

Diário Oficial do Estado, Porto Alegre, 24 dez. 1991.
RIO GRANDE DO SUL. Lei n ${ }^{\circ}$ 9.764/92.

Diário Oficial do Estado, Porto Alegre, 27 nov. 1992.

RIO GRANDE DO SUL. Lei $\mathrm{n}^{0}$ 10.582/95. Diário Oficial do Estado, Porto Alegre, 27 nov. 1995. RIO GRANDE DO SUL. Lei $\mathrm{n}^{\circ}$ $11.475 / 00$. Diário Oficial do Estado, Porto Alegre, 2 maio 2000. RIO GRANDE DO SUL. Regimento Interno do Conselho Estadual de Contribuintes do Rio Grande do Sul. Diário Oficial do Estado, Porto Alegre, 10 maio 1951.

RIO GRANDE DO SUL. Regimento Interno: Resolução TARF n ${ }^{\circ}$ 1/2002. Diário Oficial do Estado, Porto Alegre, 23 dez. 2002. 


\section{AGRADECIMENTOS}

A pesquisa para a elaboração deste trabalho contou com a colaboração dos funcionários do TARF e da Biblioteca da Secretaria da Fazenda, com destaque para a bibliotecária Sra. Rosane Koschewitz, a quem agradecemos. 